\title{
A Cross-Sectional Epidemiological Study to Evaluate the Awareness of Patients And Private Dental Practitioners Regarding Dental Implant Therapy in Nashik.
}

\author{
Dr. Supriya Murkute ${ }^{1}$, Dr. Amol Beldar ${ }^{2}$, Dr. Priya Thakkar ${ }^{3}$, \\ Dr. Mitali Thamke \\ ${ }^{1,3,4} \mathrm{PG}$ student of Periodontology; MGVs KBH dental college and hospital Nashik \\ ${ }^{2}$ Reader and guide of Periodontology; $M G V s$ KBH dental college and hospital Nashik
}

\begin{abstract}
In the present era, dental implant is most recent and promising treatment modality for tooth replacement. However it's awareness is disputable. Hence, the aim of the study was to evaluate the knowledge of patients and private dental practitioners (PDP's) towards implant dentistry and how the dentists assess, acquire and integrate this into everyday practice. Epidemiological study was conducted among patients who attended the OPD of MGV's KBH Dental College \& Hospital and private dental practitioners in Nashik. A total of 472 patients and 241 dentists were given a separate self-administered structured questionnaire and was asked to record their responses. Simple percentage evaluation was done for the responses obtained. Among patients, only $31 \%$ patients heard about dental implant as tooth replacement option which shows the lack of awareness regarding dental implant. Most of PDP's (92\%) who advocated dental implant therapy, are not satisfied about their knowledge about the implant at BDS level and need more training at internship (44\%) and 4th year (23\%).This survey depicts that although most of the PDP's \& patients are interested in implant as an option for replacing tooth, but cost is the major inhibiting factor. Also, implementing basic knowledge \& skill of implant dentistry at Under Graduate level will go a long way in developing this treatment modality.
\end{abstract}

Keywords: Awareness, Dental implant, Private dental practitioners (PDP's), Survey, Tooth replacement option.

\section{Introduction}

The well-being and quality of life is often affected by the common oral changes and conditions of the individuals. The loss or removal of the one or more of the natural teeth may results in disabilities in daily living activities such as impaired eating, speaking, or social embarrassment. In such conditions, the role of the dental practitioner is very important regarding the choice of the replacement of the teeth. So, the replacement of missing teeth is very important. There are various treatment modalities are available for the replacement of missing teeth by removable prosthesis, fixed prosthesis, dentures and recently by dental implant.

Nowadays, the main goal of the modern dental treatments is to restore the patient's normal function, speech, esthetics, as well as health. In the past few decades, the modern dentistry has changed tremendously due to the arrival of dental implants are first-choice restorative tool for the rehabilitation of the partially edentulous or completely edentulous jaws Besides, the number of dental implants inserted each year, the information available to the patients regarding the procedure and success rate is more compounded in developing nations like India. However as dental implant costs are higher as compared to bridges and dentures, they are conveyed as costly option to the patient or not offered at all. The strong evidence of successful implant therapy for patients who receive this treatment and the increasing number of patients who rely on their dentists to provide more reliable information means that private dental practitioners should have sound knowledge and comprehensive understanding of the complete implant treatment protocol ${ }^{2}$.

In the present scenario, it is common to see a patient coming to the clinics with already having implant placed in mouth or asking for implants placement. It has become mandatory for the general dental practitioner to be familiar with the basic knowledge about dental implants, so that they can refer to further specialists. Therefor our goal was to assess the sources, level of awareness and need for information about dental implants among patients and to evaluate the knowledge of patients and private dental practitioners towards implant dentistry and how the dentist assess, acquire and integrate this knowledge into their everyday practice.

\section{Material And Methods}

2.1 Study design, area and population: The present cross sectional survey was conducted on patients attending the outpatient ward department of periodontology, MGV's KBH Dental College and Hospital, Nashik and evaluated general dental practitioners in Nashik in year 2015. 
2.2 Sample size and sampling technique: Sample of 250 PDP's \& 500 Patients were included in the survey randomly from the OPD of MGV's KBH dental college \& hospital, Panchvati, Nasik, Maharashtra.

2.3 Survey tool: A printed questionnaire was used to evaluate the awareness about dental implants which is different for patient and practitioners regarding the basic information about dental implant. Total 26 closed ended multiple choice questionnaire was designed to assess the patient's \& PDP's acceptance, awareness and knowledge about dental implants as a treatment modality for replacement of missing teeth. The questionnaire was prepared bilingually (English and Marathi) to correspond with the reading and comprehension levels of patients with different levels of education. Questionnaire was distributed to the patients coming in department OPD of Periodontics, Oral surgery, Prosthodontics and Oral Medicine. Additional explanation will be given if the patient didn't understand any particular aspect of the form. Also, to the private dental practitioners in Nashik. Demographic data, socioeconomic status and level of education were also assessed.

2.4 Statistical analysis: All the data was filtered, tabulated and subjected to Simple percentage evaluation was done for the responses obtained. This data formed the basis for assessment. Total 472 forms from patients and 241 forms from PDP's were accepted for assessment while incompletely filled form were rejected. Frequency tables were used to determine the proportion level of variables among surveyed patients.

\section{Results}

Out of the total participants among the females patients were slightly predominant than males. About $62 \%$ of participants were in the age group of $28-38$ and 39-49 year. Patients education status was also included, $88 \%$ of the patients had some kind of formal education. Table 1 summarizes the demographic data of the interviewed population. Out of total participants among private dental practitioners most of practitioners $(46 \%)$ are male were in age group of 25-35 and 36-47 year. Among that higher number $(67 \%)$ of practitioners were graduates (BDS) only. Table 2 summarizes the demographic structures of interviewed practitioners. There were total 26 questions in the questionnaire 13 for each patients and practitioners out of which some of the details are mentioned in table 3 and table 4 respectively.

\section{Discussion}

Oral health means much more than just healthy teeth. Good oral health is a major resource for social, economic and personal development of individuals ${ }^{3}$. Teeth are required for mastication, phonetics, esthetics, structural balance and for the comfort of an individual. With the loss of teeth, the above functions are impaired resulting in physical and physiological, psychological trauma to the individual ${ }^{4}$.Dental implant treatment has been at the forefront of clinical dental practice for over a decade now. With increasing success rate of dental implant treatment more patients are opting implants as premier choice for replacement of missing teeth. Around one million dental implants are inserted each year, worldwide ${ }^{5}$.

In our study among 472 patients, most of the patients knew removable and fixed crown prosthesis as option for tooth replacement while only $31 \%$ patients heard about dental implant which shows the lack of awareness regarding dental implant. Similar findings by Rupal J Shaha et al in $2013^{6}$ that only $41.33 \%$ patients among 300 heard about dental implant. In the study done by Nirmal Raj et al in 2014 showed that out of the 249 individuals $100 \%(\mathrm{~N}-249), 43.77 \%(\mathrm{~N}=109), 80.7 \%(\mathrm{~N}=201)$ and $10.84 \%(\mathrm{~N}=27)$ had the knowledge of complete denture, Removable Partial Denture, Fixed Partial denture and Implants respectively ${ }^{7}$. However, studies conducted by Zimmer et al $(1992)^{8}$, Berge $(2000)^{9}$ \& Tepper et al $(2003)^{10}$ showed level of awareness was 77,70 , and $72 \%$ respectively which was higher than our study. The awareness found was less in our study as compared to above mentioned studies that may be because of low level of education and the study was conducted in hospital where most of the patients were from rural community.

Regarding the source of information $72 \%$ patients dentists followed by media which has similar findings with the studies conducted by Johny SA et al (2010) ${ }^{11}$. However, studies conducted by Zimmer et al (1992), showed media was found to be the main source of information about implants, while dentists were only source of information in (17\%). Berge (2000) ${ }^{9}$ and Best (1993) ${ }^{12}$ also found that, the media was the main source of information; while dentists are the secondary one. Akagawa et al (1988) ${ }^{13}$ in their study found that, dentists provide not more than $20 \%$ of the information. Among 472 individuals $95 \%$ patients are interested in listening the information about dental implant which shows positive attitude and acceptance for new techniques. But the barrier for the implant acceptance among the patients is high cost (49\%) followed by multiple visits (24\%) which are similar to study conducted by Tepper et al (2003) ${ }^{9}$.

In our study all the practitioners prefer to do radiographic planning whether it is found mostly Computed Tomography (CT ) 46\%, Orthopantomograph (OPG) \& Intra Oral Periapical Radiograph (IOPAR) 30\%, Orthopantomograph (OPG) 20\% while Intra Oral Periapical Radiograph (IOPAR) 4\%. Prabhath Ramakrishnan et al (2014) found mostly CBCT, OPG and IOPA was advised, 87.33\% only OPG and only $4.66 \%$ OPG in combination with an IOPA and $4.33 \%$ ordered OPG with $\mathrm{CT}^{14}$. 
In another study, dentists believed, after some years of working, that their education in relation to dental prostheses was not sufficient and asked for the promotion of such education in dental schools. Haghighi et al. only $26.6 \%$ reported that they were provided sufficient information about implant treatment procedure during their B.D.S. program, while a majority (73.3\%), and acknowledged a lack of sufficient information. The vast majority $(95.7 \%)$ reported that more information about implant treatment should be provided in the B.D.S. curriculum ${ }^{15}$. Basutkar NA found $80 \%$ of the dentists felt that the training in implants should be provided or undertaken at post-doctoral level after individual attains minimum skills required to practice conventional dentistry. $74 \%$ of dentists strongly felt that the training given at undergraduate level was not sufficient and $67 \%$ of them were of the opinion that there was scope to incorporate more didactic clinical sessions of dental implants at undergraduate level ${ }^{16 .}$

Similarly in our study PDP's offered dental implant as replacement option but most of them (92\%) were not satisfied about their knowledge about the implant at BDS level and needed more training at internship (44\%) and 4th year (23\%).In another study, it was emphasized that despite improvements in dentists' abilities and skills which are acquired due to clinical experience, there is the fact that the practitioner experiences some drawbacks in some aspects after graduating from the university ${ }^{17}$, necessitating the continuation of learning. In addition, another study showed a higher knowledge level in dentists taking part in continuous education programs and seminars compared to those not participating in such programs. The monitoring and maintenance of those implants may then fall upon general dental practitioner. General practitioner should have the ability to maintain these implants and recognize associated pathology if present. In cases of peri-implantitis, the dental practitioner should be knowledgeable regarding suitable interventions ${ }^{18}$.

In our study most of the PDPs (96\%) think of focusing on dental implant practice and offer dental implant for replacement of missing teeth which shows the positive attitude towards the implant as newer advance treatment modality, similar results found by Naggapa R et al it was very positive attitude of both the dental $(88.1 \%)$ and medical $(76.1 \%)$ practitioners that they were willing to gain more knowledge regarding the procedure so that they can implement it in their clinical practice ${ }^{19}$. But due to some barrier as mention above there is lack in dental implant practice in India that has to be taken in consideration in future perspectives. Basutkar NA found that about $80 \%$ of general dental practitioner do not practice dental implants while Less than half $(34 \%)$ practicing themselves while some $(28 \%)$ refer to or call consultant $(80 \%){ }^{16}$. So, there is a need for incorporating to update the basic knowledge \& skills related to implant dentistry at UG level to develop this branch of dentistry which is beneficial to the dental patients also.

\section{Tables}

Table 1. Demographic characteristics of the participants:

\begin{tabular}{|c|c|c|c|}
\hline & & $\begin{array}{l}\text { No. of Patients } \\
(472)\end{array}$ & $\begin{array}{l}\text { Percentage } \\
(\%)\end{array}$ \\
\hline Age & $(17-27)$ year & 46 & 10 \\
& $(28-38)$ year & 94 & 19 \\
& $(39-49)$ year & 134 & 28 \\
& $>=50$ year & 198 & 41 \\
\hline Gender & Male & 225 & 48 \\
& Female & 247 & 52 \\
\hline Educational level & Illiterate & 88 & 18 \\
& Basic school & 135 & 28 \\
& Secondary school & 115 & 24 \\
& Graduated & 98 & 20 \\
& Post graduated & 36 & 7 \\
\hline
\end{tabular}

Table 2. Demographic characteristics of private dental practitioners:

\begin{tabular}{|c|c|c|c|}
\hline & & $\begin{array}{c}\text { No of dentists } \\
(241)\end{array}$ & Prcentage \% \\
\hline Age & 25-35 year & 63 & 26 \\
& 36-47 year & 112 & 46 \\
& 48-58 year & 66 & 27 \\
\hline Gender & Male & 156 & 64 \\
& Female & 85 & 26 \\
\hline Educational & BDS & 162 & 67 \\
level & Post & 79 & 23 \\
& graduate & & \\
\hline
\end{tabular}


Table 3. Results of Patient questionnaire to evaluate knowledge and expectations regarding implant:

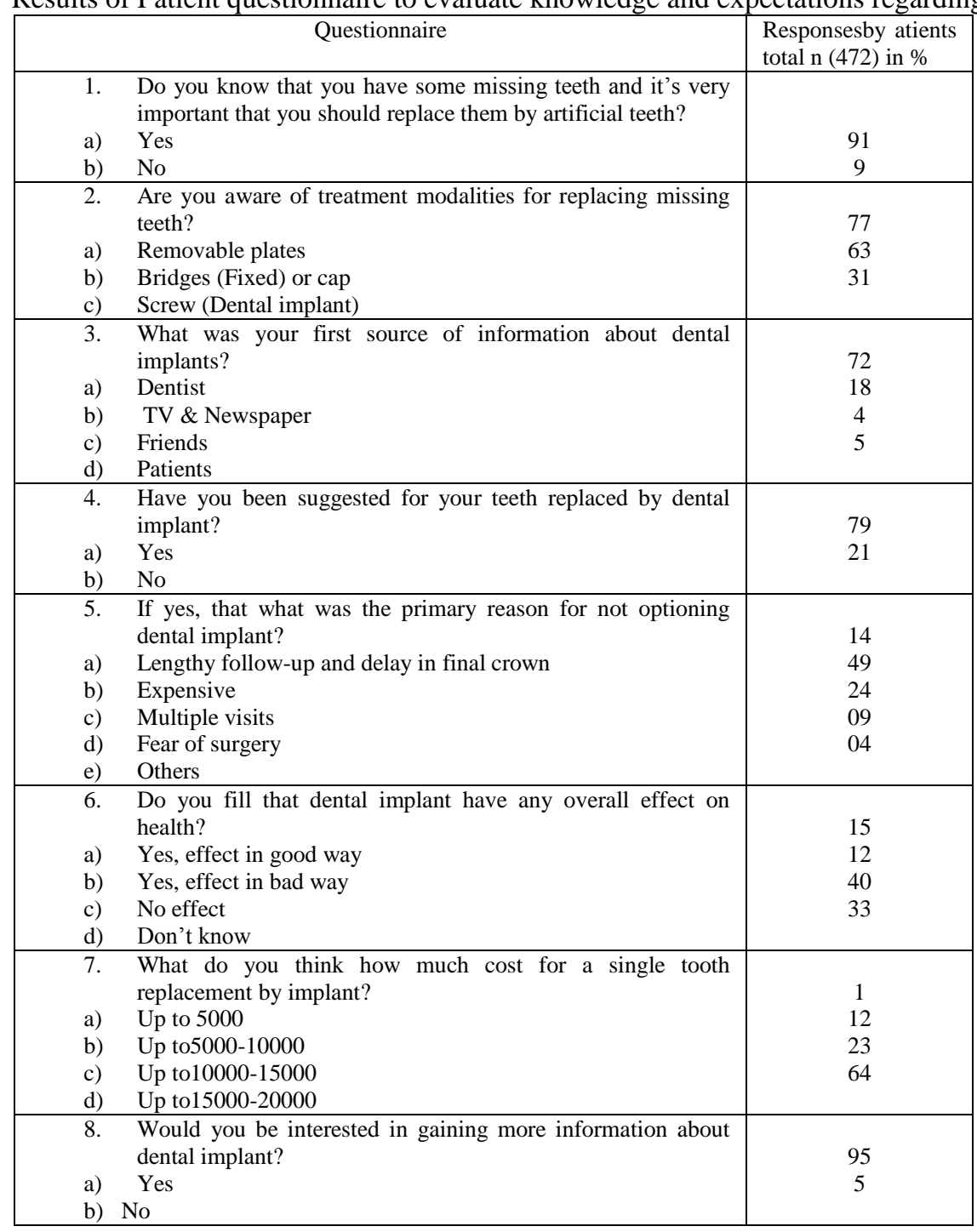

Table 4. Results of questionnaire response obtained from Private Dental Practitioners:

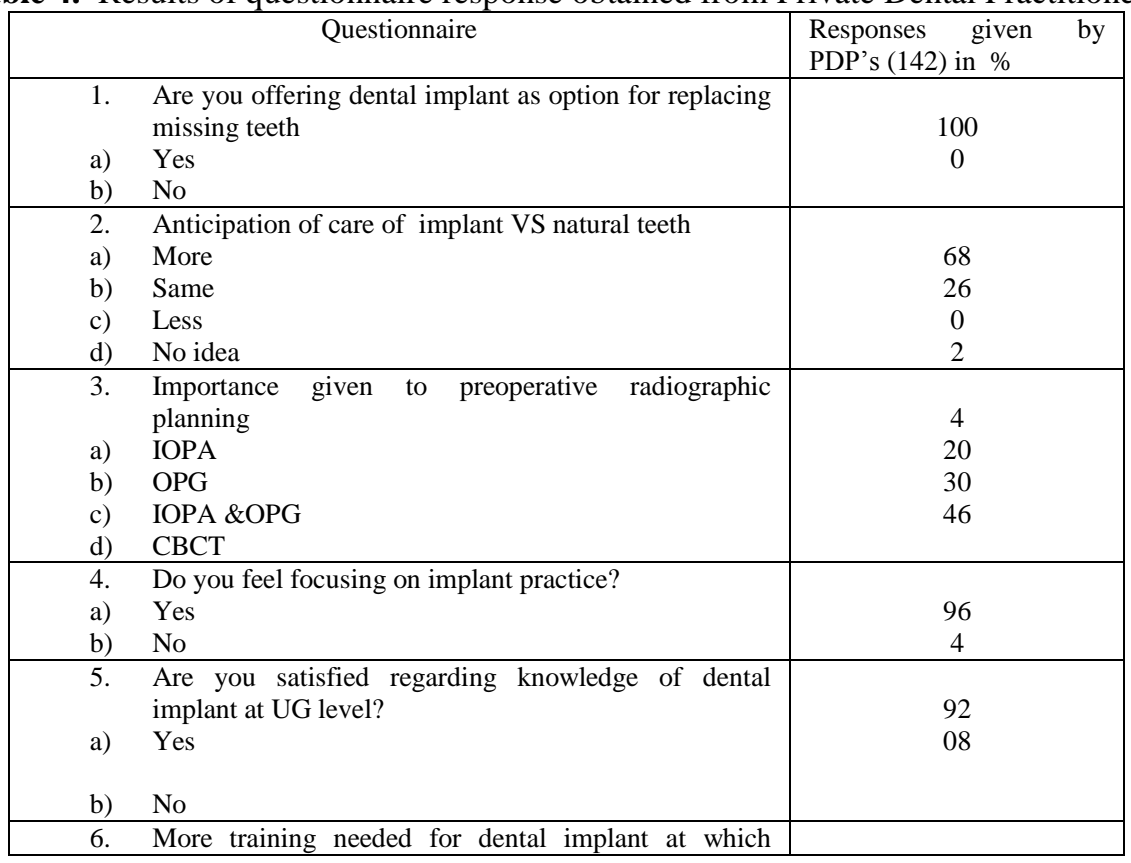




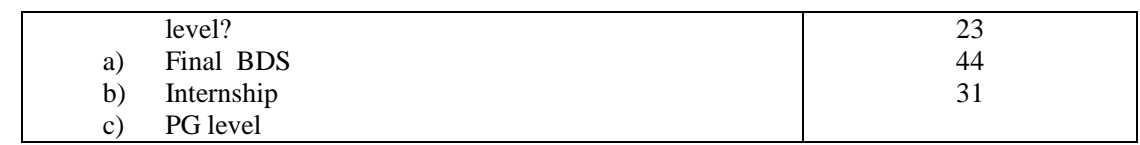

\section{Conclusion}

In spite there is a lack of awareness among patients regarding dental implant as treatment option for replacing missing teeth but most of patients $95 \%$ are willing to know about implant if information is provided. That shows the need of various dental programs like camp and mobile dental vans to change attitudes, spread awareness, and extend treatment to provide information to the people regarding dental implant. Also, the high treatment cost is the major barrier for implant acceptance.

Considering the low level of knowledge of dentists in the present study it is suggested that instructions be provided in direct and distant-learning continuous learning programs through scientific journal and other means to the dentists. Most of dentists suggest dental implant as treatment option to the patients and wants to focus on dental implant practice, but they need more training \& experience of dental implant therapy at undergraduate level. This strategy should be implemented in the academics at BDS level.

\section{References}

[1]. Suprakash B, Ahammed AR, Thareja A, Kandaswamy R, Nilesh K, Bhondwe Mahajan S. Knowledge and attitude of patients toward dental implants as an option for replacement of missing teeth. J Contemp Dent Pract 2013; 14(1):115-8.

[2]. Chaudhary S, Gowda TM, Kumar TA, Mehta DS. Knowledge and attitudes of dental interns in Karnataka state, India, regarding implants. J Dent Educ 2013; 77(10):1365-70.

[3]. Khan SA, Dawani N, Bilal S (2012). Perceptions and myths regarding oral health care amongst strata of low socio economic community in Karachi, Pakistan. J. Pakistan Med. Ass. 62(11):1198-203.

[4]. Suresh S, Sharma S (2010). A clinical survey to determine the awareness and preference of needs of a complete denture among complete edentulous patients. J. Int. Oral health.3 (2):65-70.

[5]. Pommer B, Zechner W, Watzak G, Ulm C, Watzek G, Tepper G. Progress and trends in patients' mindset on dental implants. I: level of information sources of information and need for patient information. Clin Oral Implants Res 2011; 22(2):223-9.

[6]. Rupal J Shaha, Anandmayee Chturvedi, Hemal Agarwal. Dental implant as a treatment modality: awareness survey among people of Ahmedabad, Int J Prosthodont Restor Dent 2014; 4 (2):35-38.

[7]. Nirmal Raj et al. Knowledge, Attitudes towards Prosthodontics Rehabilitation and Utilization of Dental Services among Songadh and Amargadh PopulationJournal of Dentistry, Medicine and Medical Sciences Vol. 3(1) pp. 1-6, January, 2014

[8]. Zimmer CM, Zimmer WM, Williams J, Liesener J. Public awareness and acceptance of dental implants. Int J Oral Maxillofac Implants 1992; 7(2):228-32.

[9]. Berge TI. Public awareness, information sources and evaluation of oral implant treatment in Norway. Clin Oral Implants Res 2000; 11(5):401-8.

[10]. Tepper G, Haas R, Mailath G, Teller C, Zechner W, Watzak G, et al. Representative marketing-oriented study on implants in the Austrian population. I. Level of information, sources of information and need for patient information. Clin Oral Implants Res 2003; 14(5):621-33.

[11]. Johany SA, Zoman HA, Juhaini MA. Refeai MA. Dental patients' awareness and knowledge in using dental implants as an option in replacing missing teeth: A survey in Riyadh, Saudi Arabia. Saudi Dent J 2010; 22:183-8.

[12]. Best HA. Awareness and needs of dental implants by patients in New South Wales. Aust Prosthodont J 1993; 7:9-12.

[13]. Akagawa Y RY, Matsumoto T. Attitudes of removable denture patients toward dental implants. J Prosthet Dent. 1998; 3: 362-4.

[14]. Prabhath Ramakrishnan et al. A Survey on Radiographic Prescription Practices in Dental Implant Assessment among Dentists in Kerala, India. OHDM - Vol. 13 - No. 3 - September, 2014.

[15]. Haghighat A, Bonakdariyan M, Ghaffari M. Evaluation of Isfahan dental practitioners' awareness about dental implants. Isf Den J 2009; 6; 493-9.

[16]. Basutkar NA. Assessment of knowledge related to implant dentistry in dental practitioners of north Karnataka region, India. J Dent Implant 2013; 3:26-8.

[17]. Verrijt AH, van der Plaats RE, Plasschaert AJ. Dentist's opinion about their dental education in Nijmegen, the Netherlands from 1990-1997. Nederlands tijdschrift voor tandheelkunde 2000; 107; 3-7.

[18]. Hicklin SP, Albrektsson T. Theoretical knowledge in implant dentistry for undergraduate students. Eur J Dent Educ 2009; 13:25-3

[19]. Naggapa R et al. Knowledge, Attitude and Practice of the Dental and Medical Practitioners Regarding Dental Implants Journal of International Oral Health 2016; 8(1):44-52. 